\title{
Rendimento de grãos e eficiência no uso de água de arroz irrigado em função da época de semeadura
}

\author{
Grain yield and water use efficiency in irrigated rice according to sowing date
}

\author{
Gerson Meneghetti Sarzi Sartori ${ }^{I^{*}}$ Enio Marchesan ${ }^{\mathrm{I}}$ Cristian Fernandes Azevedo ${ }^{\mathrm{I}}$ \\ Nereu Augusto Streck ${ }^{\mathrm{I}}$ Rodrigo Roso ${ }^{\mathrm{I}}$ Lucas Lopes Coelho $^{\mathrm{I}}$ Maurício Limberger de Oliveira ${ }^{\mathrm{I}}$
}

RESUMO

Uma das práticas desafiadoras de manejo é aumentar a produção de arroz utilizando menos água. $O$ experimento foi realizado nas safras de 2010/11 e 2011/12 na área experimental da Universidade Federal de Santa Maria, Rio Grande do Sul. O objetivo foi avaliar o rendimento de grãos e a eficiência do uso de água na semeadura no início e final da época recomendada. Os tratamentos foram as épocas de semeadura (01/10/10 e 01/12/10) safra 2010/11, e (27/09/11 e 07/12/11) safra 2011/12, com cinco repetições, e a cultivar utilizada foi a 'IRGA 424'. Não houve diferença no volume de água aplicado entre as épocas de semeadura, com volume médio de 5757 e $8420 \mathrm{~m}^{3}$ $h a^{-1}$, respectivamente, para safra 2010/11 e 2011/12. A época de semeadura afetou o rendimento de grãos, com rendimento de 13 e $24 \%$ a mais nas semeaduras do início da época $(01 / 10 / 10$ e 27/09/11), comparado às semeaduras do final da época (01/12/10 e 07/12/11), respectivamente. A semeadura realizada no início da época recomendada (início de outubro) proporciona maior rendimento de grãos e maior eficiência no uso de água.

Palavras-chave: precipitação pluvial, radiação solar, potencial produtivo, Oryza sativa.

\section{ABSTRACT}

One of the challenging management practices is to increase rice production using less water. The study was conducted during the harvest of 2010/11 and 2011/12 in the experimental field of Universidade Federal de Santa Maria, Rio Grande do Sul State, Brazil. The objective was to evaluate the yield and water use efficiency at sowing at beginning and end of the recommended time. Treatments were at planting dates (10/01/10 and 12/01/10) 2010/11 harvest, and (9/27/11 and 12/07/11) 2011/12 harvest, with five replicates, the cultivar used was the 'IRGA 424'. There was no difference in the amount of applied water between sowing times, with an average of 5757 and $8420 \mathrm{~m}^{3} \mathrm{ha}^{-1}$, respectively for season 2010/11 and 2011/12. The sowing date affected grain yield, with yields of 13 and $24 \%$ more in the beginning of the sowing season (10/01/10 and 9/27/11) compared to the end of the sowing date (12/01/10 and 12/07/11), respectively. Sowing early in the recommended period (early October) provides greater yield and more water use efficiency.

Key words: rainfall, solar radiation, potential yield, Oryza sativa.

\section{INTRODUÇÃO}

O arroz irrigado é assunto em vários debates envolvendo conservação de água em nível mundial, por estar entre as espécies que mais utilizam irrigação e por ser classificada como muito exigente quanto ao uso de água durante o ciclo de desenvolvimento (NOLDIN et al., 2001; MACHADO et al., 2006). Diante da preocupação com a produção de alimentos e a crise mundial da água, elevar a eficiência de uso de água, é uma meta de extrema importância para a sustentabilidade da produção de arroz.

Estratégias visando à maior eficiência de água em arroz estão sendo estudadas em diversas partes do mundo por diversos pesquisadores (TOESCHER et al., 1997; BOUMAN \& TUONG, 2000; MACHADO et al., 2006; AHMAD et al., 2008; JALOTA et al., 2009; MAHAJAN et al., 2009; YAO et al., 2012). Entre as estratégias, está o uso de diferentes sistemas de irrigação (contínuo e intermitente), densidades de plantas, cultivares de

IDepartamento de Fitotecnia, Centro de Ciências Rurais (CCR), Universidade Federal de Santa Maria (UFSM), 97105-900, Santa Maria, RS, Brasil. E-mail: gersonmss@yahoo.com.br. *Autor para correspondência. 
diferentes ciclos (curto, médio e tardio), híbridas e convencionais, diferentes momentos de supressão da irrigação e épocas de semeadura do arroz. A maioria dessas estratégias são eficazes, porém, algumas delas apresentam certas restrições à sua utilização, pelo aumento de custos e necessidade de precisão no controle da água de irrigação e diminuição no rendimento de grãos. No entanto, é desafio produzir mais alimento com menos água, o que, de acordo com HAEFELE et al. (2009), pode ser alcançado reduzindo as perdas de água por evaporação, percolação e escoamento.

A época de semeadura do arroz irrigado, associada às condições meteorológicas como temperatura e radiação solar, constitui-se num dos fatores relacionados ao rendimento de grãos do arroz (SLATON et al., 2003; LINSCOMBE et al., 2004, FREITAS et al., 2008; AKBAR et al., 2010; MORADPOUR et al., 2011; LACK et al., 2012) e pode trazer benefícios em termos de redução da quantidade e aumento da eficiência do uso de água da lavoura, pois, em semeaduras realizadas no início do período recomendado (outubro), normalmente, as precipitação pluviais são maiores e as perdas de água por evaporação são menores, já que a radiação solar e a temperatura do ar são mais baixas, quando comparado com semeaduras realizadas no final da época recomendada (dezembro). MAHAJAN et al. (2009), avaliando diferentes épocas de semeadura no rendimento de grãos e no uso de água do arroz, no estado de Punjab, noroeste da Índia, em que o clima da região é semi-árido com precipitação média anual de 400 a $700 \mathrm{~mm}$, encontraram maior eficiência no uso de água na semeadura realizada no início da época (15 de junho), comparado com 25 de junho e 05 de julho. Como as regiões produtoras de arroz são distintas em termos de disponibilidade climática, há necessidade de se conhecer melhor os efeitos da época de semeadura do arroz, no rendimento de grãos e no uso de água nas condições do Rio Grande do Sul, para que se possa manejar a lavoura de forma sustentável, com menor custo, e mínimo impacto ao ambiente.

Em vista disso, o trabalho teve por objetivo avaliar o rendimento de grãos e a eficiência do uso de água de arroz irrigado na semeadura no início e final da época recomendada para a Depressão Central do Rio Grande do Sul, uma das regiões orizícolas de grande relevância deste estado.

\section{MATERIAL E MÉTODOS}

O experimento foi realizado na safra agrícola de 2010/11 e 2011/12 na área experimental de várzea da Universidade Federal de Santa Maria (UFSM), em solo classificado como Planossolo Háplico Eutrófico arênico, pertencente à unidade de mapeamento Vacacaí. $\mathrm{Na}$ área em que foi realizado o experimento, o horizonte A variou de 0 a $0,2 \mathrm{~m}$ e o Bt de 0,2 a $0,4+\mathrm{m}$, segundo metodologia proposta por SANTOS et al. (2005). Os tratamentos foram épocas de semeadura $(01 / 10 / 10$ e 01/12/10) safra 2010/11 e (27/09/11 e 07/12/12) safra 2011/12, com cinco repetições.

A cultivar utilizada foi a IRGA 424, a qual possui ciclo de 132 dias. A semeadura foi realizada na quantidade de $90 \mathrm{~kg} \mathrm{ha}^{-1}$ de semente, com espaçamento de $0,17 \mathrm{~m}$, no sistema de cultivo mínimo, o qual consistiu de preparo antecipado da área e, após, houve formação de cobertura vegetal, sendo esta dessecada com glyphosate na dose de $1,08 \mathrm{~kg}$ i.a. ha ${ }^{-1}$, em área sistematizada. A adubação de base foi de $15 \mathrm{~kg} \mathrm{ha}^{-1}$ de nitrogênio $(\mathrm{N}), 45 \mathrm{~kg} \mathrm{ha}^{-1}$ de $\mathrm{P}_{2} \mathrm{O}_{5}$ e $90 \mathrm{~kg} \mathrm{ha}^{-1}$ de $\mathrm{K}_{2} \mathrm{O}$, conforme a indicação da análise de solo. $\mathrm{O} \mathrm{N}$ foi aplicado na quantidade de $150 \mathrm{~kg} \mathrm{ha}^{-1}$, dividido nas quantidades de $15 \mathrm{~kg} \mathrm{ha}^{-1}$ por ocasião da semeadura, $90 \mathrm{~kg} \mathrm{ha}^{-1}$ no perfilhamento (V3/V4) e $45 \mathrm{~kg} \mathrm{ha}^{-1}$ na diferenciação da panícula (R0) segundo escala de COUNCE et al. (2000). Os demais tratos culturais foram realizados conforme as recomendações técnicas para a cultura (SOSBAI, 2010).

$\mathrm{O}$ volume de água aplicado foi avaliado através de medidor de vazão com diâmetro nominal de 4". Para quantificar o volume, as parcelas de aproximadamente $28 \mathrm{~m}^{2}$ de área foram isoladas com taipas ronda, de altura média de $0,6 \mathrm{~m}$, e a entrada de água foi individualizada para cada parcela. $\mathrm{O}$ sistema de irrigação utilizado foi o intermitente, com a irrigação de cada parcela formando lâmina de água de aproximadamente de $0,1 \mathrm{~m}$ e, após, deixavase evapotranspirar até aproximadamente $0,02 \mathrm{~m}$ de lâmina, com objetivo de armazenar a água, em eventuais precipitações. A irrigação foi suspensa aos 15 dias após a floração plena (R2), aproximadamente, 112 dias após a semeadura. Com a finalidade de evitar as perdas de água por infiltração lateral, foi mantida água ao entorno das parcelas através de taipas de contenção, mantendo assim a mesma carga hidráulica em todas as parcelas.

O rendimento de grãos foi avaliado através da colheita de $4,5 \mathrm{~m}^{2}$ de área útil em cada parcela, quando os grãos se encontravam com grau de umidade médio de $22 \%$. Após a trilha, limpeza e pesagem dos grãos com casca, os dados foram corrigidos para $13 \%$ de umidade e convertidos em $\mathrm{kg} \mathrm{ha}^{-1}$. O número de panículas $\mathrm{m}^{-2}$ foi determinado uma semana antes da colheita, através da contagem das panículas em um metro de linha previamente demarcado, sendo nesta 
mesma área realizada a coleta de quinze panículas por ocasião da colheita para a estimativa do número de grãos por panícula, massa de mil grãos e esterilidade de espiguetas.

A eficiência do uso de água foi obtida pela divisão do rendimento de grãos pelo volume de água aplicado. Avaliou-se também a contribuição de água advinda das precipitações pluviais, através do monitoramento da precipitação com pluviômetro instalado ao lado do experimento. Por ocasião da irrigação definitiva, colocou-se em cada parcela uma estaca com altura de $0,1 \mathrm{~m}$ acima da superfície do solo, após, regularam-se todas as saídas de água das parcelas (despontes) no mesmo nível da extremidade das estacas $(0,1 \mathrm{~m}$ de altura) para mensuração da lâmina de água antes e após as precipitações, para quantificar a contribuição de água das precipitações pluviais.

Os valores de radiação solar global, precipitação pluvial e temperatura do ar foram obtidos da estação meteorológica automática e os valores de evaporação foram obtidos pelo tanque Classe A da estação meteorológica convencional do $8^{\circ}$ DISME/ INMET, localizado no Departamento de Fitotecnia da UFSM, a aproximadamente 500m do experimento. Para análise estatística, realizou-se, para cada safra, o teste $\mathrm{t}$ bilateral para duas amostras independentes em nível de $5 \%$ de probabilidade, para comparar as épocas de semeadura.

\section{RESULTADOS E DISCUSSÃO}

O volume de água aplicado não diferiu entre as épocas de semeadura nas safras 2010/11 e
2011/12, com volume médio aplicado para cada safra de, respectivamente, 5.757 e $8.420 \mathrm{~m}^{3}$ ha $^{-1}$ (Tabela 1 ). Na safra 2010/11, nos meses de outubro e novembro, a precipitação foi de, respectivamente, 62 e $41 \%$ a menos que a normal (Figura 1C), provavelmente, devido ao fenômeno La Niña, cujo sinal é de chuvas abaixo da normal na primavera. Por outro lado, nos meses de dezembro, fevereiro e abril, a precipitação foi de, respectivamente, 26, 41 e $39 \%$ a mais que a normal. Já em janeiro e março foi de 18 e $60 \%$ a menos que a normal. Com isso, a contribuição de água pelas chuvas foi semelhante entre as duas épocas de semeadura, com $4.080 \mathrm{~m}^{3} \mathrm{ha}^{-1}$ na semeadura realizada no início do período recomendado (01/10) e $3.792 \mathrm{~m}^{3} \mathrm{ha}^{-1}$ para a semeadura realizada no final do período (01/12), explicando, em parte, a semelhança entre as épocas de semeadura quanto ao volume de água aplicado nesta safra.

$\mathrm{Na}$ safra 2011/12, o volume de água aplicado foi $32 \%$ superior ao volume de água aplicado na safra 2010/11. Embora a contribuição da água das chuvas na semeadura realizada ao final do período recomendado (07/12) foi $37 \%$ superior à semeadura realizada no início do período recomendado (27/09), isso não se refletiu em diferença significativa quanto ao volume de água aplicado. Isso pode estar relacionado à maior evaporação ocorrida no estabelecimento inicial da cultura (janeiro), o que demandou maior volume de água, em comparação à semeadura do início do período em que o estabelecimento inicial foi no mês de novembro. O maior volume de água aplicado nessa safra está relacionado à menor precipitação ocorrida principalmente nos meses de novembro, dezembro

Tabela 1 - Volume de água aplicado (VAA), contribuição de água das precipitações pluviais (CP), esterilidade de espiguetas (E), número de panículas $\mathrm{m}^{-2}(\mathrm{NP})$, massa de mil grãos (MMG), número de grãos por panícula (NGP), rendimento de grãos (R) e eficiência de uso da água (EUA), na cultivar IRGA 424, em duas épocas de semeadura, na safra 2010/11 e 2011/12. Santa Maria, RS. 2012.

\begin{tabular}{|c|c|c|c|c|c|c|c|c|}
\hline Épocas & VAA $m^{3} h a^{-1}$ & $\mathrm{CP} \mathrm{m}^{3} \mathrm{ha}^{-1}$ & $\mathrm{E} \%$ & NP & MMG $g$ & NGP & $\mathrm{R} \mathrm{kg} \mathrm{ha}^{-1}$ & EUA \\
\hline & $5001^{\mathrm{ns}}$ & & & $-a^{\mathrm{ns}}$ & 10/11--- & & & 100 \\
\hline $01 / 10 / 10$ & $5901^{1 / 4}$ & 4080 & $9 \mathrm{~b}$ & $761^{11 s}$ & $24,8^{119}$ & $81 \mathrm{~b}$ & 11334 a & $1,92 \mathbf{a}$ \\
\hline $01 / 12 / 10$ & 5614 & 3792 & $13 \mathrm{a}$ & 673 & 24,7 & $88 \mathrm{a}$ & $9876 \mathrm{~b}$ & $1,76 \mathrm{~b}$ \\
\hline Média & 5757 & 3936 & 11 & 717 & 24,7 & 84 & 10605 & 1,84 \\
\hline $\mathrm{CV} \%$ & 3,4 & & 18,5 & 11,6 & 2,3 & 2,4 & 4,8 & 6,0 \\
\hline $27 / 09 / 11$ & $8453^{\text {ns }}$ & 2040 & $12,9^{\mathrm{ns}}$ & 801 a & $23,7 \mathrm{~b}$ & $61,9^{\mathrm{ns}}$ & 9972 a & $1,2 \mathbf{a}$ \\
\hline $07 / 12 / 11$ & 8386 & 3252 & 12,5 & $659 \mathrm{~b}$ & $25 \mathrm{a}$ & 68,1 & $7610 \mathrm{~b}$ & $0,9 \mathrm{~b}$ \\
\hline Média & 8420 & 2646 & 13 & 730 & 24 & 65 & 8791 & 1 \\
\hline $\mathrm{CV} \%$ & 4,1 & & 13,7 & 6,9 & 3,7 & 9,7 & 2,6 & 6,7 \\
\hline
\end{tabular}

${ }^{\text {ns }}$ Não significativo em nível $\mathrm{P} \leq 0,05$;

* Médias não seguidas da mesma letra minúscula na coluna diferem entre si pelo teste t bilateral em nível de $5 \%$ de probabilidade.

Ciência Rural, v.43, n.3, mar, 2013. 


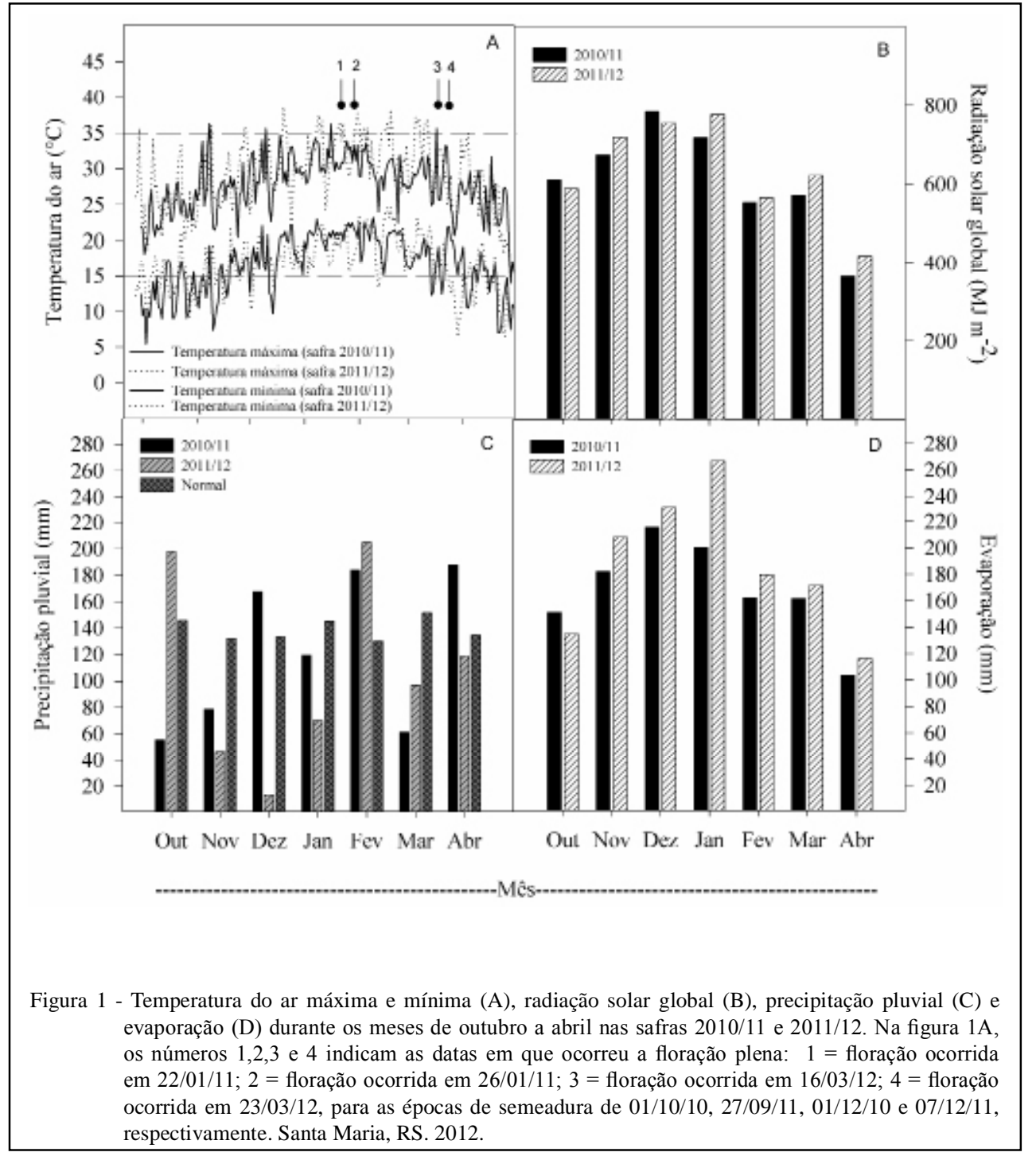

e janeiro, com precipitação de, respectivamente, 65 , 90 e $52 \%$ abaixo do normal (Figura 1C). Com isso, houve menor contribuição de água pelas chuvas, com contribuição de, respectivamente, 50 e $14 \%$ a menos que a safra de 2010/11 para as épocas de semeadura no início e final do período recomendado.

Além da menor precipitação, outro fator que pode ter contribuído para um maior volume de água aplicado é a maior evaporação ocorrida (Figura 1D). De maneira geral, na safra 2011/12, comparado à safra 2010/11, as temperaturas máximas do ar (Figura 1A) e a radiação solar global (Figura 1B) foram superiores em grande parte do período, o que deve ter contribuído para elevação da evaporação, pois o aumento da temperatura contribui para elevação do déficit de pressão de vapor. MAHAJAN et al. (2009) também associam a exigência de água na cultura do arroz com a demanda evaporativa.

Esses resultados estão próximos aos obtidos por MACHADO et al. (2006), os quais encontraram volumes de água aplicado variando de 5.431 a 6.422 e de 5.374 a $5.852 \mathrm{~m}^{3} \mathrm{ha}^{-1}$, respectivamente, para as safras 2000/01 e 2001/02 em diferentes sistemas de cultivos, na mesma área experimental do presente estudo, com a cultivar ELPASO 144, semeada em 03 de novembro para ambas as safras agrícolas. Já TOESCHER et al. (1997), no sistema de irrigação intermitente, na mesma condição de clima e solo do presente estudo, encontraram volume de água aplicado de 8.764 e $8.579 \mathrm{~m}^{3} \mathrm{ha}^{-1}$, respectivamente, para as cultivares BR-IRGA 409 e IAC-47. O sistema de irrigação intermitente permite grande economia 
no uso de água, chegando a 24 e $38 \%$ nas safras de 2009 e 2010, respectivamente, comparado com a irrigação contínua (YAO et al., 2012), pois ele permite armazenar grande parte da água advinda das precipitações pluviais.

Embora a época de semeadura não tenha influenciado no volume de água aplicado nas duas safras avaliadas, ela interferiu no rendimento de grãos da cultura (Tabela 1). Na safra 2010/11, o maior rendimento de grãos foi $11.334 \mathrm{~kg} \mathrm{ha}^{-1}$ para a semeadura realizada no início do período recomendado, $13 \%$ a mais que a semeadura no final do período, uma redução de $24 \mathrm{~kg} \mathrm{ha}^{-1} \mathrm{dia}^{-1}$ no rendimento, a partir de 01/10. Comportamento semelhante a essa safra ocorreu na safra 2011/12, em que o maior rendimento de grãos foi na semeadura realizada no início do período recomendado, com rendimento de grãos $24 \%$ maior em comparação à época de semeadura no final do período, uma redução de $33 \mathrm{~kg} \mathrm{ha}^{-1} \mathrm{dia}^{-1}$, a partir de 27/09.

O maior rendimento de grãos obtido na semeadura realizada no início do período recomendado pode ser explicado em parte pela maior disponibilidade de radiação solar (Figura 1B) e melhores condições de temperatura (Figura 1A), durante o período reprodutivo da cultura (floração e enchimento de grãos), comparado à menor disponibilidade neste período na semeadura realizada no final da época recomendada. Além das condições meteorológicas, o aumento da esterilidade de espiguetas observado na semeadura, no final do período recomendado na safra de 2010/11, e o menor número de panículas produzidos na safra 2011/12 podem ter contribuído para o menor rendimento de grãos.

$\mathrm{O}$ aumento da esterilidade de espiguetas pode estar relacionado às temperaturas mais baixas (Figura 1A) durante a formação do grão de pólen, pois FARRELL et al. (2006) relatam que baixa temperatura nessa época pode causar aumento da esterilidade de espigueta. Além disso, outro fator que pode ter contribuído para maior esterilidade de espiguetas foi as temperaturas elevadas na antese, que, de acordo com JAGADISH et al. (2007), temperaturas superiores a $35^{\circ} \mathrm{C}$ nesse estádio, por mais de uma hora, pode diminuir a fertilidade de espiguetas em arroz. GUNAWARDENA et al. (2003), avaliando 12 horas por dia de temperatura de $21,4 / 21^{\circ} \mathrm{C}$ (dia/ noite), comparado a $18 / 13^{\circ} \mathrm{C}$ (dia/noite) em diferentes alturas de lâmina de irrigação, durante sete dias no desenvolvimento do micrósporo de arroz, encontraram, de forma geral, maior esterilidade de espiguetas na temperatura mais baixa $\left(18 / 13^{\circ} \mathrm{C}\right)$. Em trabalho realizado por PEDRO JÚNIOR et al. (1995), avaliando a relação entre os valores de temperatura média do ar durante o período crítico e a produtividade relativa (\%), encontraram a temperatura de $25^{\circ} \mathrm{C}$, como temperatura ótima na análise em conjunto de diferentes cultivares de arroz irrigado.

Esses resultados estão de acordo com SLATON et al. (2003) e FREITAS et al. (2008), os quais relatam que os melhores rendimentos de grãos são obtidos quando as semeaduras são realizadas no início da época recomendada e tendem a diminuir quando realizadas no final.

AKBAR et al. (2010), também avaliando diferentes épocas de semeadura na cultura do arroz no Pakistão, encontraram que a época de semeadura afeta o rendimento de grãos da cultura, e associaram o aumento do rendimento às condições meteorológicas favoráveis durante o crescimento e desenvolvimento da cultura, como aumento dos valores médios de temperatura acumulada e horas de radiação solar. Nesse sentido, fazer coincidir o período reprodutivo da cultura do arroz com as melhores condições de temperatura e radiação solar traz resposta positiva em termos de rendimento de grãos (ISLAM \& MORISON, 1992; SLATON et al., 2003; FREITAS et al., 2008; KATSURA et al., 2008; SAFDAR et al., 2008; LACK et al., 2012).

A época de semeadura de arroz irrigado, além de influenciar no rendimento de grãos, influenciou na eficiência do uso de água, com uso de água mais eficiente na semeadura, realizada no início do período recomendado em ambas as safras avaliadas (Tabela 1). A maior eficiência no uso de água está relacionada ao maior rendimento de grãos ocorrido na semeadura do início do período, pois aumentar o rendimento de grãos com o mesmo volume de água é uma estratégia que proporciona maior eficiência no uso de água. Esse resultado corroborando MAHAJAN et al. (2009), os quais encontraram maior eficiência no uso de água na semeadura do início da época (15 de junho), associando essa eficiência ao maior rendimento de grãos.

Portanto, a época de semeadura de arroz irrigado é uma prática de manejo importante que afeta o rendimento de grãos da cultura e a eficiência do uso de água. Assim, deve-se priorizar semeaduras no início do período recomendado, visando a um maior rendimento de grãos, que proporciona uso mais eficiente de água.

Ciência Rural, v.43, n.3, mar, 2013. 


\section{CONCLUSÃO}

A semeadura realizada no início da época recomendada (início de outubro) proporciona maior rendimento de grãos e maior eficiência no uso de água, devido à cultura se desenvolver em condições meteorológicas adequadas como temperatura, radiação solar e precipitação pluvial.

\section{AGRADECIMENTOS}

Ao Conselho Nacional de Desenvolvimento Científico e Tecnológico (CNPq), pela bolsa de Mestrado concedida ao primeiro autor e pela bolsa de produtividade em pesquisa para o segundo autor. À Fundação de Apoio à Pesquisa do Estado do Rio Grande do Sul (FAPERGS), pela bolsa de Iniciação Científica concedida ao terceiro autor. Ao CNPq e à FAPERGS, pelo auxílio financeiro para realização da pesquisa.

\section{REFERÊNCIAS}

AKBAR, N. et al. Effect of different sowing dates on the yield and yield components of direct seeded fine rice (Oryza sativa L.). Journal of Plant Breeding and Crop Science, v.22, n.10, p.312$315,2010$.

AHMAD, S. et al. Water and radiation use efficiencies of transplanted rice (Oryza sativa L.) At different plant densities and irrigation regimes under semi-arid environment. Pakistan Journal of Botany, v.40, n.1, p.199-209, 2008.

BOUMAN, B.A.M; TUONG, T.P. Field water management to save water and increase its productivity in irrigated lowland Rice. Agricultural Water Management, v.1615, p.1-20, 2000. Disponível em: <http://www.sciencedirect.com/science/article/pii/ S0378377400001281>. Acesso em: 07 maio, 2012. doi: 10.1016/ S0378-3774(00)00128-1.

COUNCE, P.A. et al. A uniform, objective and adaptive system for expressing rice development. Crop Science Society of America, v.40, n.2, p.436-443, 2000.

FARREL, T.C. et al. Genotypic variation for cold tolerance during reproductive development in rice: Screening with cold air and cold water. Field Crops Research, v.98, p.178-194, 2006. Disponível em: <http://www.sciencedirect.com/science/article/pii/ S0378429006000256>. Acesso em: 07 maio, 2012. doi: 10.1016/j. fcr.2006.01.003.

FREITAS, T.F.S. et al. Produtividade de arroz irrigado e eficiência da adubação nitrogenada influenciadas pela época da semeadura. Revista Brasileira de Ciência do Solo, v.32, p.2397-2405, 2008. Disponível em: <http://www.scielo.br/scielo.php?pid=S0100$06832008000600018 \&$ script $=$ sci_abstract $\&$ tlng=pt $>$. Acesso em: 07 maio, 2012. doi: 10.1590/S0100-06832008000600018.

GUNAWARDENA, T.A. et al. Low temperature induced spikelet sterility in rice. II. Effects of panicle and root temperatures. Australian Journal of Agricultural Research, v.54, n.10, p.947956, 2003.

HAEFELE, S.M. et al. Transpiration efficiency of rice (Oryza sativa L.). Field Crops Research, v.111, p.1-10, 2009.
Disponível em: <http://www.sciencedirect.com/science/article/pii/ S0378429008001901>. Acesso em: 07 maio, 2012. doi: 10.1016/j. fcr.2008.09.008

ISLAM, M.S.; MORISON, J.I.L. Influence of solar radiation and temperature on irrigated rice grain yield in Bangladesh. Field Crops Research, v.30, p.13-28, 1992.

JAGADISH, S.V.K. et al. High temperature stress and spikelet fertility in rice (Oryza sativa L.). Journal of Experimental Botany, v.58, n.7, p.1627-1635, 2007. Disponível em: <http:// jxb.oxfordjournals.org/content/58/7/1627>. Acesso em: 07 maio, 2012. doi: $10.1093 / \mathrm{jxb} / \mathrm{erm} 003$.

JALOTA, S.K. et al. Integrated effect of transplanting date, cultivar and irrigation on yield, water saving and water productivity of rice (Oryza sativa L.) in Indian Punjab: field and simulation study. Agricultural Water Management, v.96, p.1096-1104, 2009.

KATSURA, K. et al. The high yield of irrigated rice in Yunnan, China. 'A cross-location analysis. Field Crops Research, v.107, p.1-11, 2008. Disponível em: <http://www.sciencedirect.com/ science/article/pii/S0378429007002596>. Acesso em: 08 maio, 2012. doi: 10.1016/j.fcr.2007.12.007.

LACK, S. et al. The effects of planting date on grain yield and yield components of rice cultivars. Advances in Environmental Biology, v.6, n.1, p.406-413, 2012.

LINSCOMBE, S.D. et al. Rice response to planting date differs at two locations in Louisiana. Crop Management, 2004. Disponível em: <http://www.plantmanagementnetwork.org/pub/ cm/research/2004/rice/>. Acesso em: 08 maio, 2012. doi: 10.1094/ CM-2004-0130-01-RS.

MACHADO, S.L.O. et al. Consumo de água e perdas de nutrientes e de sedimentos na água de drenagem inicial de arroz irrigado. Ciência Rural, v.36, n.1, p.65-71, 2006. Disponível em: <http://www.scielo.br/scielo.php?script=sci_arttext\&pid $=$ S0103-84782006000100010>. Acesso em: 08 maio, 2012. doi: 10.1590/S0103-84782006000100010.

MAHAJAN, G. et al. Yield and water productivity of rice as affected by time of transplanting in Punjab, India. Agricutural Water Management, v.26, p.525-532, 2009. Disponível em: <http:// www.sciencedirect.com/science/article/pii/S0378377408002369>. Acesso em: 08 maio, 2012. doi: 10.1016/j.agwat.2008.09.027.

MORADPOUR, S. et al. Effect of planting date and plant density on yield and yield components of rice. Ecology, Environment and Conservation, v.17, n.2, p.251-256, 2011.

NOLDIN, J.A. et al. Persistência do herbicida clomazone no solo e na água quando aplicado na cultura do arroz irrigado, sistema pré-germinado. Planta Daninha, v.19, n.3, p.401-408, 2001. Disponível em: <http://www.scielo.br/scielo.php?pid=S0100$83582001000300013 \&$ script $=$ sci_abstract\&tlng=pt $>$. Acesso em: 08 maio, 2012. doi: 10.1590/S0100-83582001000300013.

PEDRO JÚNIOR, M.J. et al. Estimativa da produtividade de arroz irrigado por inundação em em função da temperatura do ar e da radiação solar. Scientia Agricola, v.52, n.1. p.96 -100, 1995.

SANTOS, R.D. et al. Manual de descrição e coleta de solo no campo. 5.ed. Viçosa: SBCS, 2005. 100p. 
SAFDAR, M.E. et al. Effect of transplanting dates on paddy yield of fine grain rice genotypes. Pakistan Journal of Botany, v.40, n.6, p.2403-2411, 2008 .

SLATON, N.A. et al. Seeding date effect on rice grain yields in Arkansas and Louisiana. Agronomy journal, v.95, n.1, p.218223,2003

SOCIEDADE SUL-BRASILEIRA DE ARROZ IRRIGADO (SOSBAI). Arroz irrigado: recomendações técnicas da pesquisa para o Sul do Brasil / 28. Reunião Técnica da cultura do Arroz Irrigado, Bento Gonçalves, RS. Porto Alegre, 2010. 188p.

TOESCHER, C.F. et al. Volume de água aplicada e produtividade do arroz sob diferentes métodos de irrigação. Revista da FZVA, v.4, n.1, p.49-57, 1997.

YAO, F. et al. Agronomic performance of high-yielding rice variety grown under alternate wetting and drying irrigation. Field Crops Research, v.126, p.16-22, 2012. Disponível em: <http:// www.sciencedirect.com/science/article/pii/S0378429011003339>. Acesso em: 08 maio, 2012. doi: 10.1016/j.fcr.2011.09.018.

Ciência Rural, v.43, n.3, mar, 2013. 